University of Nebraska - Lincoln

DigitalCommons@University of Nebraska - Lincoln

$10-15-2001$

\title{
Magnetic nanodot arrays produced by direct laser interference lithography
}

\author{
M. Zheng \\ University of Nebraska - Lincoln \\ M. Yu \\ University of Nebraska - Lincoln \\ Yi Liu \\ University of Nebraska-Lincoln, yliu@unl.edu \\ Ralph Skomski \\ University of Nebraska-Lincoln, rskomski2@unl.edu \\ Sy_Hwang Liou \\ University of Nebraska-Lincoln, sliou@unl.edu \\ See next page for additional authors
}

Follow this and additional works at: https://digitalcommons.unl.edu/physicsliou

Part of the Physics Commons

Zheng, M.; Yu, M.; Liu, Yi; Skomski, Ralph; Liou, Sy_Hwang; Sellmyer, David J.; Petryakov, V.N.; Verevkin, Yu K.; Polushkin, N.I.; and Salashchenko, N. N., "Magnetic nanodot arrays produced by direct laser interference lithography" (2001). Si-Hwang Liou Publications. 66.

https://digitalcommons.unl.edu/physicsliou/66

This Article is brought to you for free and open access by the Research Papers in Physics and Astronomy at DigitalCommons@University of Nebraska - Lincoln. It has been accepted for inclusion in Si-Hwang Liou Publications by an authorized administrator of DigitalCommons@University of Nebraska - Lincoln. 


\section{Authors}

M. Zheng, M. Yu, Yi Liu, Ralph Skomski, Sy_Hwang Liou, David J. Sellmyer, V.N. Petryakov, Yu K. Verevkin, N.I. Polushkin, and N. N. Salashchenko 


\title{
Magnetic nanodot arrays produced by direct laser interference lithography
}

\author{
M. Zheng, ${ }^{\text {a) }}$ M. Yu, Y. Liu, R. Skomski, S. H. Liou, and D. J. Sellmyer ${ }^{\text {b) }}$ \\ Center for Materials Research and Analysis and Department of Physics and Astronomy, \\ University of Nebraska, Lincoln, Nebraska 68588-0113 \\ V. N. Petryakov and Yu. K. Verevkin \\ Institute of Applied Physics of RAS, 603600 Nizhni Novgorod, Russia \\ N. I. Polushkin and N. N. Salashchenko \\ Institute for Physics of Microstructures of RAS, 603600 GSP-105 Nizhni Novgorod, Russia
}

(Received 5 September 2000; accepted for publication 20 August 2001)

\begin{abstract}
Periodic magnetic nanodot arrays have been produced on an area as large as $1 \mathrm{~cm} \times 1 \mathrm{~cm}$ by direct nanolithography using interferometric laser radiation. The dots are formed by the local annealing of sputtered amorphous $\mathrm{Co}-\mathrm{C}$ films in regions where the laser intensity is highest. At room temperature the dots exhibit ferromagnetic order and are embedded in a paramagnetic matrix. The onset of room-temperature ferromagnetism is caused by nanoscale chemical and morphological changes during dot formation and reflects the phase separation of magnetic Co-rich clusters. The present single-step nanolithography is potentially an efficient method for fabrication of patterned magnetic arrays. (C) 2001 American Institute of Physics. [DOI: 10.1063/1.1409948]
\end{abstract}

The production of magnetic nanoarrays with welldefined periodicity has been a major challenge in the areas of magnetic recording media and magnetic devices. Several methods, including electron-beam lithography, have been employed to create tiny features down to nanometer scale. ${ }^{1-6}$ Unfortunately, most methods may not be suitable for largescale device fabrication because they are multistep, expensive, and time-consuming procedures. In recent years, several groups have demonstrated that interferometric lithography is a rapid and economical way to generate large area dot arrays with periods of a few hundreds nanometers. ${ }^{3-5}$ The minimum period achievable by interferometric lithography is about $\lambda / 2$, which is $\sim 200 \mathrm{~nm}$ for the commonly used $\mathrm{Ar}^{+}$laser; significantly smaller periods might be possible with $\mathrm{x}$-ray radiation.

Conventional interferometric lithography is a multistep process, involving the interference of two laser beams of wavelength $\lambda$ which intersect on a resist-coated substrate, selective etching, and lift off. ${ }^{3}$ The process involving the resist, etching, and subsequent cleaning raises an important issue when applying it to patterned magnetic structures. In general, achieving a sufficient degree of surface cleanliness and smoothness will be of great importance. ${ }^{6}$ An approach to generate the discrete magnetic islands by a noncontact, straightforward method is highly desirable. In this letter, we report such an approach to magnetic patterning, namely direct one-step lithography involving atomic rearrangements in Co-C films. For this patterning method, we use short-pulsed (down to $10 \mathrm{~ns}$ ) interfering beams of a $\mathrm{XeCl}$ laser (308 nm). $\mathrm{Co}-\mathrm{C}$ films are chosen in this exploratory study because they form a simple system containing immiscible magnetic (Co) and nonmagnetic $(\mathrm{C})$ phases and the metastable Co carbides decompose easily into $\mathrm{Co}$ and $\mathrm{C}$ upon annealing. ${ }^{7-10} \mathrm{Mag}-$

${ }^{a)}$ Present address: MMC Technology, Inc, 2001 Fortune Dr., San Jose, CA 95131.

${ }^{\text {b)} E l e c t r o n i c ~ m a i l: ~ d s e l l m y e @ u n l n o t e s . u n l . e d u ~}$ netic properties have been studied in laterally homogenous films in both the as-deposited and annealed states. ${ }^{7,8}$ One can therefore anticipate that the behavior of laser quenched alloys is similar to that of thermally treated $\mathrm{Co}-\mathrm{C}$ films. The Co dot arrays are formed by phase separation of Co or Corich clusters under the influence of laser intensity maxima which provide local annealing.

The $\mathrm{Co}_{50} \mathrm{C}_{50}$ (at. \%) films were cosputtered onto a watercooled 7059 glass substrate and had a thickness of $40 \mathrm{~nm}$. The sputtered films were exposed to a 10-ns-pulsed excimer laser having a wavelength of $308 \mathrm{~nm}$ and a flux of $0.17 \mathrm{~J} / \mathrm{cm}^{2}$. The laser beam was split into two beams of an approximately equal intensity and then recombined, generating an interference pattern and a periodic modulation of the light intensity. The interference of the four beams leads to the formation of two-dimensional arrays of modified regions having a minimum lattice periodicity equal to half of the radiation wavelength. The size and shape of the regions depend on the incident angles of the beam, on pulse duration, and on flux. For example, our experiments sometimes employed two pairs of beams incident in mutually orthogonal planes at angles of 20 degrees (TM polarization) and 40 degrees (TE polarization); under these conditions, an anisotropic distribution of the laser intensity on the film surface is realized which results in elongated dot shapes.

The nanostructure of the films, both before and after the laser processing is somewhat complex. While the asdeposited films appear amorphous to x-ray diffraction, ${ }^{8}$ transmission electron microscopy (TEM) data show that $\mathrm{Co}-\mathrm{C}$ (Ref. 11) and $\mathrm{Fe}-\mathrm{C}$ (Ref. 12) films actually consist of nanocrystalline grains of sizes in the 1-2 $\mathrm{nm}$ range. Our earlier work ${ }^{8}$ showed that the as-deposited $\mathrm{Co}-\mathrm{C}$ films were nonmagnetic (i.e., nonferromagnetic) at room temperature, but upon annealing at temperatures in the range of $350-550{ }^{\circ} \mathrm{C}$, magnetic Co nanoparticles are formed with diameters of $10-25 \mathrm{~nm}$.

Figure 1 shows a TEM bright-field image of the $\mathrm{Co}-\mathrm{C}$ 


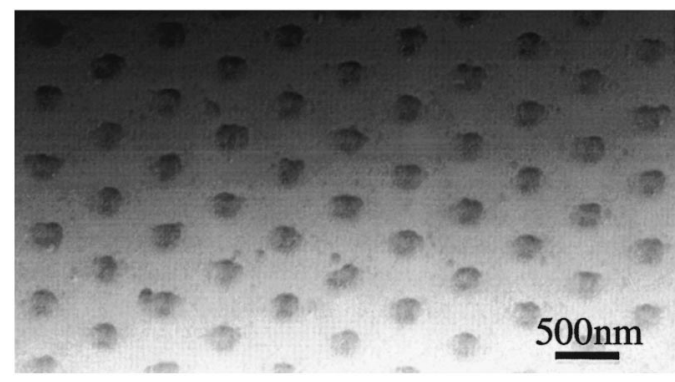

FIG. 1. TEM image of periodic arrays of patterned Co-C films.

films after laser processing. The dark regions (dots) exhibit a granular structure and the light regions between the dots (the matrix) also show evidence of granularity. The dot diameter is about $250 \mathrm{~nm}$ and the interdot spacing is about $650 \mathrm{~nm}$. Experiments with higher exposure (intensity $\times$ time) have shown that the area of the dots can be made to grow relative to the area of the matrix. However, electron diffraction experiments on the dot and matrix regions show that the differences in the nanostructure are subtle. Both are consistent with 1-2 nm grains with evidence for slightly more order in the dot regions. Evidently the degree of thermal energy delivered to the dot regions is not sufficient to create Co precipitates with diameters in the 5-10 nm range.

The films after exposure were examined by atomic force microscopy (AFM) and magnetic force microscopy (MFM). The insets on the left-hand side of Fig. 2 show AFM images of a patterned $\mathrm{Co}-\mathrm{C}$ film. The observed AFM topographical contrast most likely reflects the surface lifting in the dot regions by phase changes in carbon. Bubonneau et al. have shown that in the related $\mathrm{Fe}-\mathrm{C}$ system, the as-deposited films are composed of $\mathrm{Fe}$ nanoparticles embedded in a moreor-less graphitized C matrix. ${ }^{12}$ It is known that the graphite phase (density of $2.2 \mathrm{~g} / \mathrm{cm}^{3}$ ) can transform into amorphous one (density of $1.6 \mathrm{~g} / \mathrm{cm}^{3}$ ) under thermal/laser treatment. ${ }^{13,14}$ It is natural that this transformation is accompanied by the film thickness change. While the topographical roughness when patterning the film should decrease as laser power decreases, no detailed studies have been done.

MFM was used to investigate the magnetic properties of the nanodot arrays. The MFM images were obtained using a high coercivity MFM tip ${ }^{15}$ magnetized perpendicular to the

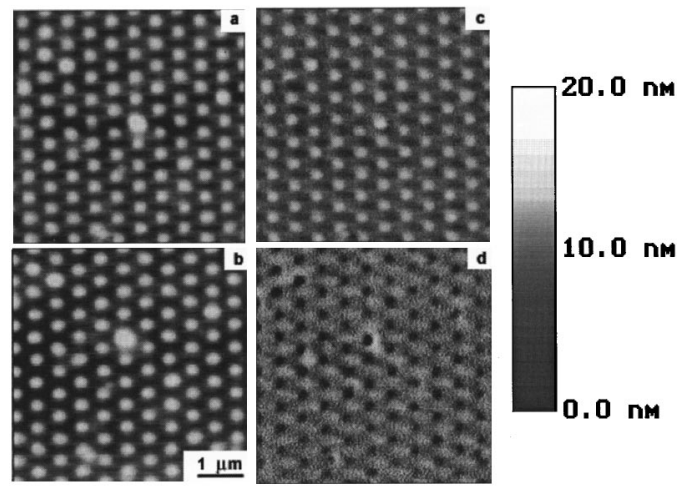

FIG. 2. AFM (a) and (b) and MFM (c) and (d) images of a periodic array of patterned $\mathrm{Co}-\mathrm{C}$ films after exposing the film to interference laser. A perpendicular field of 1700 Oe was applied parallel (c) and antiparallel (d) to the

film-plane normal during scan.
Downloaded 13 Oct 2006 to 129.93 .16 .206 . Redistribution subject to AlP license or copyright, see http://apl.aip.org/apl/copyright.jsp

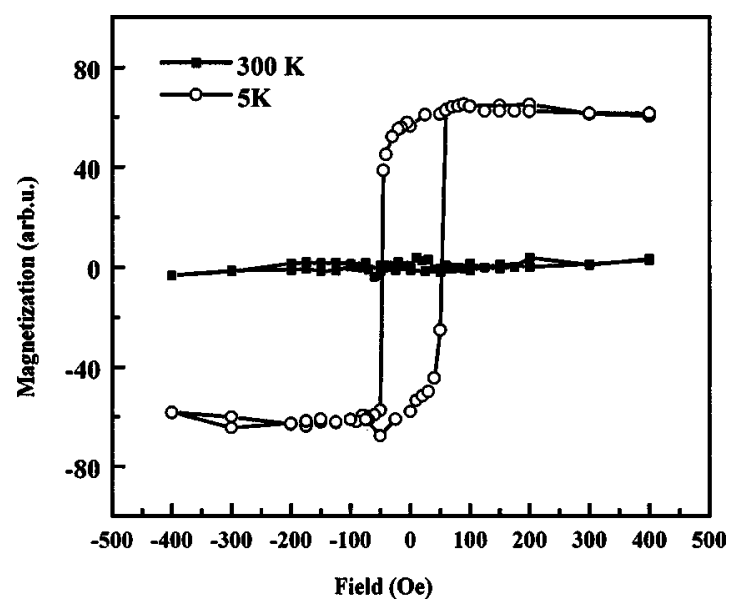

FIG. 3. Hysteresis loops for Co-C films before exposing the film to the interference laser at 5 and $300 \mathrm{~K}$.

sample surface. The tip-sample separation is about $20 \mathrm{~nm}$. Figure 2 shows AFM [Figs. 2(a) and 2(b)] and the corresponding MFM [Figs. 2(c) and 2(d)] images of Co-C composite films after they were exposed to the interference laser beams. In Figs. 2(c) and 2(d), a perpendicular field of 1700 Oe was applied in situ in directions parallel and antiparallel to the film-plane normal, respectively. The bright and dark contrast in MFM images corresponds to the strength of the stray-field gradient on the sample surface. The bright region indicates that the force between the sample and the MFM tip is repulsive. The clear MFM contrast between the two directions of the applied field indicates that the formed dots are magnetic while area between the dots is nonferromagnetic, that is, paramagnetic or superparamagnetic.

Magnetic measurements were carried out with an alternating-gradient force magnetometer (AGFM) and a superconducting quantum interference device (SQUID) magnetometer. Figure 3 shows magnetic hysteresis loops for a $\mathrm{Co}-\mathrm{C}$ film before patterning. The samples were measured by SQUID at 5 and $300 \mathrm{~K}$, respectively. The as-sputtered $\mathrm{Co}-\mathrm{C}$ film is paramagnetic at room temperature but a hysteresis loop appears at $5 \mathrm{~K}$. The temperature dependence of the magnetization of the unpatterned films, which is characterized by the absence of a phase transition, indicates that the $\mathrm{Co}-\mathrm{C}$ matrix is superparamagnetic (details will be published elsewhere). After laser patterning, hysteresis loops are detected at both $5 \mathrm{~K}$ and room temperature. Figure 4 shows the hysteresis loops for Co-C films after patterning. The loops were measured at room temperature by AGFM with the field applied in the film plane and perpendicular to the film plane. The hysteresis loops show a coercivity of the order of 100 Oe independent of the direction of the applied magnetic field. $^{16}$

The different slopes of the perpendicular loop (applied field normal to the film plane) and the in- plane loop reflect long-range magnetostatic or "demagnetizing-field" interactions. On a local scale, it is difficult to introduce a physically meaningful demagnetizing factor, ${ }^{17}$ but on a global scale there is a magnetostatic interaction contribution associated with the in-plane or perpendicular magnetization of the ferromagnetic regions. An attempt to analyze the problem along the lines of Ref. 18 requires a detailed knowledge of the sizes and shapes of the presumed Co-rich nanograins within the AIP license or copyright, see http://apl.aip.org/apl/copyright.jsp 


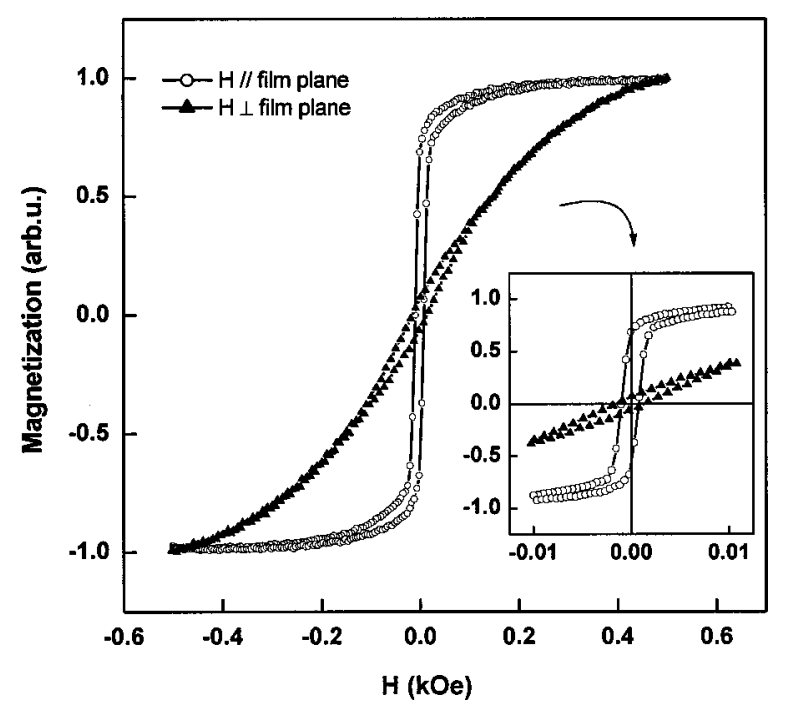

FIG. 4. Hysteresis loops of Co-C film after laser exposure, the field was applied along and perpendicular to the film plane.

dots and the dimensions of the magnetic dots themselves. In addition, one might ask whether the regions between the dots are magnetic based on the low in-plane coercive field. In fact, we have shown that increasing the laser power leads to a more homogeneously magnetized film, ${ }^{19}$ but the present work is in a regime below this threshold. The low $H_{c}$ value is compatible with domain-wall motion but comparing the dot diameter (about $250 \mathrm{~nm}$ ) with the Bloch-wall width of Co $(14 \mathrm{~nm})$ suggests that the wall motion may well be confined to a single dot. This view is supported by the MFM results of Fig. 2 and by the perpendicular coercivity. Both of these results cannot be reconciled with an essentially homogeneous magnetization state. The image of magnetic dots in a paramagnetic matrix is also consistent with the total average magnetization of the film $\left(282 \mathrm{emu} / \mathrm{cm}^{3}\right)$ and the slope of the perpendicular hysteresis loop. A crude estimate of the volume fraction of magnetic nanograins within the dots is $0.2 \pm 0.1$. It is clear that a more detailed understanding of the magnetic state of the patterned films will require considerably more work on the sub-2-nm-scale structure.

In summary, these experiments show that arrays of magnetic nanodots at room temperature are formed by exposing the homogenous $\mathrm{Co}-\mathrm{C}$ films to the interferometric laser. The pattern formation is attributed to the phase separation or precipitation of $\mathrm{Co}$ under local heating at the laser intensity maxima. $^{7-10}$ The as-sputtered $\mathrm{Co}-\mathrm{C}$ film contains some Corich nanoclusters that are superparamagnetic at room temperature. After laser patterning, there are local atomic rear- rangements that form more strongly interacting magnetic Co or Co-rich clusters and yield the observed magnetic phase at room temperature. Our preliminary experiments show that it is possible to produce arrays of magnetic dots with separation as small as about $100 \mathrm{~nm}$. Limiting factors are the thermal conductivity of the starting material and the substrate, the pulse duration, ${ }^{20}$ and the energy density distribution in the laser interference pattern. The principal advantage of the current method over classical lithography as a fabrication tool is its relative simplicity and cleanliness. Future work will focus on improving the coercivity and thermal stability by choosing systems with higher anisotropy which are suitable for both direct interference nanolithography and magnetic recording or device applications.

This work was supported by NSF, CMRA, the Nebraska Research Initiative, and the Russian Foundation of Basic Research (RFBR, No. 01-02-16445). S. H. Liou was supported by the Army Research Office, Grant No. DAAG 55-98-10014 .

${ }^{1}$ S. Y. Chou, M. Wei, P. R. Krauss, and P. B. Fisher, J. Vac. Sci. Technol. B 12, 3695 (1994).

${ }^{2}$ M. Hehn, K. Ounadjela, J. Bucher, F. Rousseaux, D. Decanini, B. Bartenlian, and C. Chappert, Science 272, 1782 (1995).

${ }^{3}$ T. A. Savas, M. Farhoud, H. I. Smith, M. Hwang, and C. A. Ross, J. Appl. Phys. 85, 6160 (1999).

${ }^{4}$ A. Fernandez, P. J. Bedrossian, S. L. Baker, S. P. Vernon, and D. R. Kania, IEEE Trans. Magn. 32, 4472 (1996).

${ }^{5}$ J. P. Spallas, R. D. Boyd, J. A. Britten, A. Fernandez, A. M. Hawryluk, J. M. Perry, and D. R. Kania, J. Vac. Sci. Technol. B 14, 2005 (1996).

${ }^{6}$ B. D. Terris, L. Folks, D. Weller, J. E. E. Baglin, A. J. Kellock, H. Rothuizen, and P. Vettiger, Appl. Phys. Lett. 75, 403 (1999).

${ }^{7}$ T. Hayashi, S. Hirono, M. Tomita, and S. Umemura, Nature (London) 381, 772 (1996).

${ }^{8}$ M. Yu, Y. Liu, and D. J. Sellmyer, J. Appl. Phys. 85, 4319 (1999).

${ }^{9}$ T. J. Konno and R. Sinclair, Acta Metall. Mater. 42, 1231 (1994).

${ }^{10}$ J.-J. Delaunay, T. Hayashi, M. Tomita, and S. Hirono, J. Appl. Phys. 82, 2200 (1997).

${ }^{11}$ Y. Liu (private communication).

${ }^{12}$ D. Babonneau, J. Briatico, F. Pretroff, T. Cabioc'h, and A. Naudon, J. Appl. Phys. 87, 3432 (2000).

${ }^{13}$ Z. Jiang, X. Jiang, W. Liu, and Z. Wu, J. Appl. Phys. 65, 196 (1989).

${ }^{14}$ V. Dupuis, M. F. Ravet, C. Tete, M. Piecuch, Y. Lepetre, R. Rivoira, and E. Ziegler, J. Appl. Phys. 68, 5146 (1990)

${ }^{15}$ S. H. Liou and Y. D. Yao, J. Magn. Magn. Mater. 190, 130 (1998).

${ }^{16}$ If the films were single crystalline, then the two in-plane coercivities would be zero (see, e.g., Ref. 13).

${ }^{17}$ R. Skomski, J. P. Liu, and D. J. Sellmyer, Phys. Rev. B 60, 7359 (1999).

${ }^{18}$ R. Skomski and J. M. D. Coey, Permanent Magnetism (Institute of Physics, Bristol, 1999), pp. 53-59.

${ }^{19}$ M. Zheng, M. Yu, Y. Liu, R. Skomski, S. H. Liou, V. N. Petryakov, Yu. K. Verevkin, N. I. Polushkin, and N. N. Salashchenko, IEEE Trans. Magn. (in press).

${ }^{20}$ J. N. Olsen, Appl. Phys. Lett. 24, 220 (1974). 